\title{
¿HA DESCENDIDO SIGNIFICATIVAMENTE LA TASA DE MORTALIDAD INFANTIL?
}

\section{HAS INFANT MORTALITY RATE SIGNIFICANTLY DECLINED? \\ ¿DESCEU SIGNIFICATIVAMENTE A MORTALIDADE INFANTIL?}

\section{Eduardo Cuestas'.}

1 Editor. Jefe-RFCM-UNC. Hospital Privado Universitario de Córdoba. Facultad de Ciencias Médicas. Universidad Nacional de Córdoba. Argentina

Palabras clave: mortalidad infantil

Keywords: infant mortality

Recibido: 2019-08-06 Aceptado: 2019-08-22

DOI: http://dx.doi.org/10.31053/1853.0605.v76.n3.25245 (c) (i) \&

Palavras-chave: mortalidade infantil

defunciones por enfermedades respiratorias entre los años 2016 y 2017 con 120 defunciones menos (23,7\% de descenso)", agregando luego que "la TMN no presentó variaciones entre estos años, se mantuvo en 6,5 por mil nacidos vivos. La primera causa de mortalidad neonatal es la prematurez, seguida de las malformaciones congénitas"2.

En la Argentina, el análisis de los últimos años, de 2000 a 2015, muestra una disminución en el número absoluto de defunciones infantiles y el descenso en la TMI de 16,6 por mil en el año 2000 a 9,7 por mil en el año 2015.

Existe en nuestro país una tendencia al descenso, que se ha mantenido a pesar de algunos aumentos que se explican por eventos como crisis sociales, económicas y/o políticas o brotes de enfermedades, especialmente respiratorias, que impactaron de manera negativa en la mortalidad infantil (ver figura 1).

de recién nacidos vivos, en la cual prevalecen los determinantes ambientales y socioeconómicos.

En general se espera una latencia de tres a diez años entre la ocurrencia de un cambio positivo o negativo en los determinantes de salud y la consecuente modificación del de la tasa de mortalidad sea este favorable o adverso.

$\mathrm{C}$ a d a $\mathrm{n}$ a c i m i e n to y c a d a defunción ocurridos en nuestro país se registran en un certificado legal y un informe estadístico. Los informes estadísticos de nacidos vivos (IENV) y de defunciones (IED) son consolidados a nivel jurisdiccional y nacional. Cada año, la Dirección de Estadísticas de Información de Salud (DEIS) del ex Ministerio de Salud de la Nación publica las Estadísticas Vitales, elaboradas a partir de los informes estadísticos correspondientes ${ }^{1}$. Recientemente las autoridades sanitarias nacionales nos informaron que "Argentina logró importante descenso de la mortalidad infantil" indicando que "la TMI disminuyó de 9,7 por mil nacidos vivos en 2016 a 9,3 en 2017, lo que representó una reducción de 5\% entre 2016 y 2017", más adelante afirmaron que "la disminución de la TMI fue atribuible principalmente a la disminución de la tasa de mortalidad postneonatal ya que la TMN no presentó cambios. En gran medida, esta baja se atribuye a la disminución de las

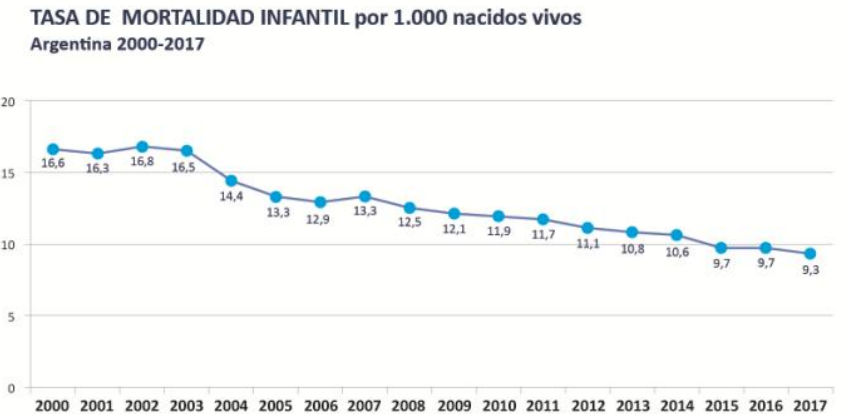

Figura $N^{\circ} 1$ TMI Argentina 2007-2017

Durante el año 2016 se produjo un ascenso de la TMI respecto a 2015 para luego descender en 2017 respecto a 2016 como puede observarse en la tabla 1.

Tabla $\mathrm{N}^{\circ} 1$ Tasa de Mortalidad Infantil (TMI) por mil nacidos vivos Argentina 2015-2017

\begin{tabular}{ccccc}
\hline Año & Defunciones & $\begin{array}{c}\text { Nacidos } \\
\text { vivos }\end{array}$ & TMI & IC 95\% \\
\hline 2017 & 6579 & 704609 & 9,34 & 9,11 a 9,56 \\
2016 & 7093 & 728035 & 9,74 & 9,52 a 9,97 \\
2015 & 7445 & 770040 & 9,67 & 9,45 a 9,89
\end{tabular}

Si se realizamos un análisis cuidadoso de los datos de las TMI desde 2015 a 2017 se observa claramente que los intervalos de confianza de $95 \%$ se superponen (ver figura 2), lo que en forma inequívoca significa que no hubo una disminución significativa en las TMI.
Las políticas de lucha contra la mortalidad infantil deben ser el resultado de una política de estado sostenida, independiente de los gobiernos de turno y sus logros o fracasos deben transmitirse con veracidad y cautela a la población, tanto por las autoridades como por los medios de comunicación masiva. 


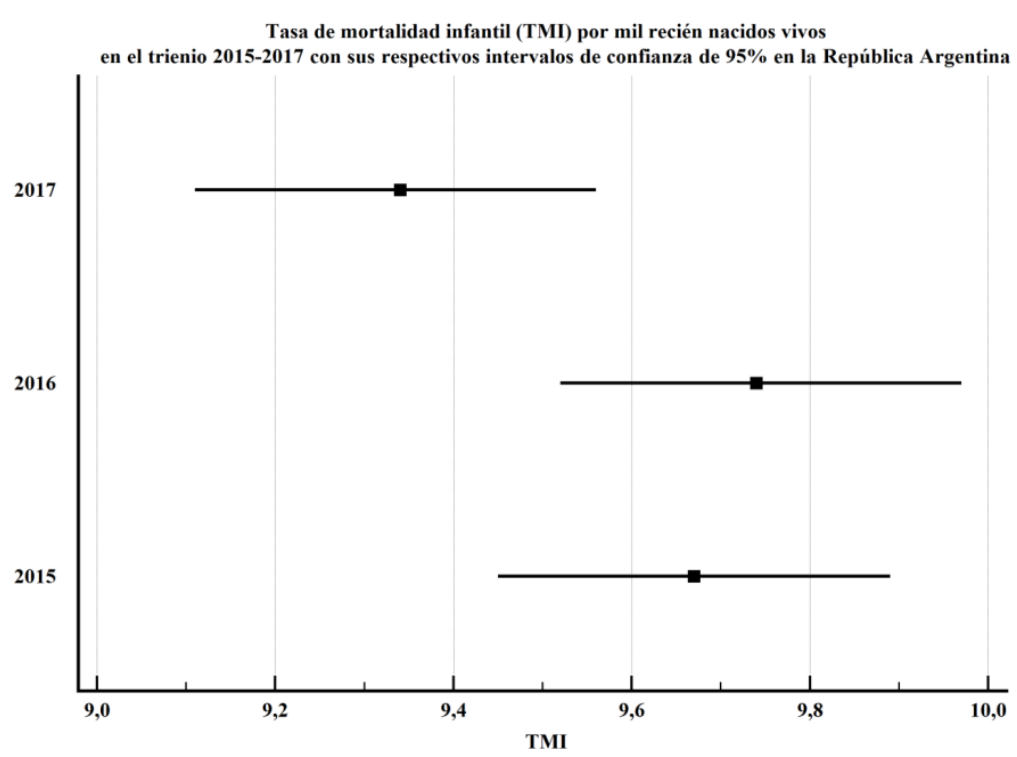

Figura $\mathrm{N}^{\circ}$ 2. Tasa de mortalidad infantil (TMI) por mil recién nacidos vivos en el trienio 2015-2017 con sus respectivos intervalos de confianza de $95 \%$ en la República Argentina

\section{Bibliografía}

1 Ministerio de Salud y Desarrollo Social. Presidencia de la Nación Argentina. Estadísticas Vitales [Internet]. Dirección de Estadísticas e Información en Salud. [citado 1 de agosto de 2019]. Disponible en: http://www.deis.msal.gov.ar/index.php/estadisticasvitales/

2 Ministerio de Salud y Desarrollo Social. Presidencia de la Nación Argentina. Argentina logró importante descenso de la mortalidad infantil y materna [Internet]. Argentina.gob.ar. 2019 [citado 1 de agosto de 2019]. Disponible en: https://www.argentina.gob.ar/noticias/argentina-logro-importantedescenso-de-la-mortalidad-infantil-y-materna 